\title{
Validation of Serum Biomarkers Derived from Proteomic Analysis for the Early Screening of Preeclampsia
}

\author{
Aggeliki Kolialexi, ${ }^{1}$ Dimitrios Gourgiotis, ${ }^{2}$ George Daskalakis, ${ }^{3}$ Antonis Marmarinos, ${ }^{2}$ \\ Alexandra Lykoudi, ${ }^{1}$ Danai Mavreli, ${ }^{1}$ Ariadni Mavrou, ${ }^{1}$ and Nikolas Papantoniou ${ }^{3}$ \\ ${ }^{1}$ Department of Medical Genetics, Athens University, "Aghia Sofia" Children's Hospital, 11527 Athens, Greece \\ ${ }^{2} 2$ nd Department of Pediatrics, Athens University, 11527 Athens, Greece \\ ${ }^{3} 1$ st Department of Obstetrics \& Gynecology, Athens University, 11528 Athens, Greece \\ Correspondence should be addressed to Aggeliki Kolialexi; akolial@med.uoa.gr
}

Received 8 September 2014; Accepted 27 November 2014

Academic Editor: Irene Rebelo

Copyright (C) 2015 Aggeliki Kolialexi et al. This is an open access article distributed under the Creative Commons Attribution License, which permits unrestricted use, distribution, and reproduction in any medium, provided the original work is properly cited.

\begin{abstract}
Aim. To examine the potential value of previously identified biomarkers using proteomics in early screening for preeclampsia (PE). Methods. 24 blood samples from women who subsequently developed PE and 48 from uncomplicated pregnancies were obtained at 11-13 weeks and analysed after delivery. Cystatin-C, sVCAM-1, and Pappalysin-1 were quantified by ELISA. Maternal characteristics and medical history were recorded. Results. Median values of Cystatin-C, sVCAM-1, and Pappalysin-1 in the PE group as compared to controls were $909.1 \mathrm{gEq} / \mathrm{mL}$ versus $480.0 \mathrm{gEq} / \mathrm{mL}, P=.000,832.0 \mathrm{gEq} / \mathrm{mL}$ versus $738.8 \mathrm{gEq} / \mathrm{mL}, P=.024$, and $234.4 \mathrm{gEq} / \mathrm{mL}$ versus $74.9 \mathrm{gEq} / \mathrm{mL}, P=.064$, respectively. Areas under the receiver-operating characteristic curves (AUC, standard error (SE)) for predicting PE were Cystatin-C: 0.90 (SE 0.04), VCAM-1: 0.66 (SE 0.074), and Pappalysin-1: 0.63 (SE 0.083). To discriminate between cases at risk for PE and normal controls, cut-off values of $546.8 \mathrm{gEq} / \mathrm{mL}$ for Cystatin-C, $1059.5 \mathrm{gEq} / \mathrm{mL}$ for sVCAM-1, and $220.8 \mathrm{gEq} / \mathrm{mL}$ for Pappalysin-1 were chosen, providing sensitivity of $91 \%, 41 \%$, and $54 \%$ and specificity of $85 \%$, $100 \%$, and $95 \%$, respectively. Conclusions. sVCAM-1 and Pappalysin-1 do not improve early screening for PE. Cystatin-C, however, seems to be associated with subsequent PE development, but larger studies are necessary to validate these findings.
\end{abstract}

\section{Introduction}

Preeclampsia $(\mathrm{PE})$ is a pregnancy-specific syndrome characterized by hypertension and proteinuria, developing after the 20th week of gestation, in a previously normotensive woman. PE may have an early ( $<34$ weeks of gestation) or a late $(>34$ weeks of gestation) onset. The condition complicates approximately $2-8 \%$ of pregnancies and is one of the major causes of maternal, fetal, and neonatal morbidity and mortality $[1,2]$. Early identification of patients with an increased risk for PE is therefore one of the most important goals in obstetrics.

Multiple pathological pathways contribute to the final phenotype of PE. These include poor placental perfusion, defective remodelling of uteroplacental vessels in early pregnancy, maternal genetic predisposition, and vascular endothelial dysfunction [3].

Various biochemical markers have been proposed for the identification of women at risk for PE [4-10]. The majority were chosen on the basis of specific pathophysiological abnormalities that have been reported in association with PE, such as placental dysfunction, endothelial and coagulation activation, and systemic inflammation. The concentration of these biomarkers in maternal serum has been found either increased or decreased early in gestation before the onset of PE. Findings, however, have been inconsistent and none of the suggested markers have demonstrated sufficient sensitivity and specificity to allow identification of pregnancies that would benefit from increased monitoring or early preventive therapies.

Research in recent years has moved toward unbiased "systems medicine" approaches, using hypothesis-generating strategies to investigate new pathways. One promising technique is proteomics, the simultaneous analysis of thousands of peptides and proteins. Several biological fluids and fetal tissues have been successfully tested, including maternal 
plasma, urine, and CVS and several potential biomarkers for the early prediction of PE have been identified [11-13]. Kolla et al. observed elevation in 10 proteins in the PE group, as compared to normotensive control pregnant women [14]. These included clusterin, fibrinogen, fibronectin, angiotensinogen, and galectin 3, increased levels of which are known to be associated with PE. In another study, Blumenstein et al. used a combination of immunodepletion and 2D DIGE and identified 39 differentially expressed proteins in the plasma of women at 20 weeks of gestation who subsequently developed PE [15]. These proteins were mainly involved in lipid metabolism, coagulation, complement regulation, extracellular matrix remodelling, protease inhibitor activity, and acutephase responses. Another prospective study by Rasanen et al., using serum proteomics, showed distinct maternal serum proteomic profiles associated with preclinical and/or clinical PE [16].

The aim of the present study was to evaluate three potential proteomic biomarkers, namely, Cystatin-C (P01034), vascular cell adhesion protein-1 (sVCAM-1) (P19320), and Pappalysin-1 (Q13219). These proteins were chosen from a list of potential biomarkers for the detection of women with early and severe preclinical and/or clinical PE provided by Rasanen et al., for which monoclonal antibodies were commercially available. Cystatin-C and sVCAM-1 were found to be substantially increased in maternal serum in PE cases while levels of Pappalysin-A were decreased.

\section{Material and Methods}

In this retrospective and case-control study, peripheral blood samples were obtained from 1050 Caucasian pregnant women, during their first routine hospital visit at 11-13 weeks of gestation (mean $12.1 \pm 0.6$ weeks) in a large maternity hospital. Following a $5 \mathrm{~min}$ centrifugation at $2000 \mathrm{rpm}$, the cleared maternal serum was collected, aliquoted, and stored at $80^{\circ} \mathrm{C}$.

Clinical data on these patients were collected by the obstetricians involved in the project, using a preestablished questionnaire [17]. All participants were normotensive at the time of blood sampling and had no renal dysfunction or proteinuria.

When pregnancy outcome was known from hospital medical records, it was revealed that 24 out of 1050 women developed PE, 2 of which required delivery at $<32$ weeks of gestation. Cystatin-C, sVCAM-1, and Pappalysin-A were measured in the 24 samples coming from these women and from 48 unaffected controls (1:2 ratio). Samples used as controls came from women with similar gestational age and duration of storage as those of the study group. All samples were analysed in duplicate. None of the samples were previously thawed and refrozen.

PE was defined according to the World Health Organization guidelines, which include an elevated systolic $(\geq 140 \mathrm{mmHg}$ ) and/or diastolic $(\geq 90 \mathrm{mmHg})$ blood pressures on repeated measurements and proteinuria $(\geq 2+$ as measured by dipstick).
The study was approved by the Athens University Committee on Ethics and in all cases written informed consent was obtained prior to blood drawing.

\section{Methods}

3.1. Enzyme-Linked Immunoassays. Cystatin-C, VCAM-1, and Pappalysin-A were quantified using the respective Human Cystatin-C, Human sVCAM-1, and Human Pappalysin-A assays (R\&D Systems, Abington, UK) according to the manufacturer's protocols. Following a 15 min centrifugation at $16000 \mathrm{~g}$, the cleared serum was tested in duplicate at a dilution of $1: 1$ for Cystatin-C, 1:20 for sVCAM-1, and 1:30 for Pappalysin-A. Assay sensitivities were $0.102 \mathrm{ng} / \mathrm{mL}$ for Cystatin-C, $0.6 \mathrm{ng} / \mathrm{mL}$ for sVCAM-1, and $0.053 \mathrm{ng} / \mathrm{mL}$ for Pappalysin-A. The intra-assay coefficients of variation were $4.6 \%$ for Cystatin-C, 3.5\% for sVCAM-1, and $4.3 \%$ for Pappalysin-A.

3.2. Statistical Analysis. Descriptive statistics for continuous parameters consisted of medians, whereas categorical variables were expressed as percentages. Patient characteristics of cases and controls were compared with the Mann-Whitney rank test for continuous variables or the Fisher's exact test for categorical variables, when appropriate. Comparisons of the biochemical data between the two study groups were performed with the Mann-Whitney rank test. Subsequently, receiver-operating characteristic (ROC) curves were calculated, and values for area under curve (AUC) with corresponding standard errors were estimated. Binary logistic regression was performed in order to determine the effect of each variable studied on risk assessment for PE. Statistical analysis was performed with the Statistical Package for Social Sciences version 20.0 (SPPS Inc., Chicago, IL, USA).

\section{Results}

Maternal and neonatal characteristics of cases and controls included in the study are presented in Table 1 . There was no difference in maternal age between patients who developed $\mathrm{PE}$ and controls, but prepregnancy body mass index (BMI) was significantly higher in the PE group $(P<.001)$. Median BMI was $27.8 \mathrm{~kg} / \mathrm{m}^{2}$ (range 9.5) in PE cases and $24.8 \mathrm{~kg} / \mathrm{m}^{2}$ (range 4.2 ) in controls (Figure 1(a)). Furthermore, more women were nulliparous in the PE group as compared to controls. Thirty-five women in the control group and 12 in the PE group declared smoking regularly during pregnancy. As expected, patients with PE gave birth earlier than controls. Seven delivered preterm $(<37$ weeks of gestation) and two before the 34th week, at 27 and 30 weeks, respectively, due to uncontrollable high blood pressure and generalised edema. Both neonates, although premature, survived the first month after birth. Women in the control group delivered at term. The newborn's birth weight was lower in women with $\mathrm{PE}$ as compared to controls. Birth weight of 11 newborns from women who developed PE was at or below the 10th percentile. Additionally in 2 cases birth weigh was below the 5th percentile. All growth restricted neonates survived. 
TABLE 1: Maternal and neonatal characteristics of cases and controls included in the study [17].

\begin{tabular}{|c|c|c|c|}
\hline & Controls $(n=48)$ & $\mathrm{PE}(n=24)$ & Statistics \\
\hline Maternal age (y) & $\begin{array}{c}32.2 \\
{[28.8-37.3]}\end{array}$ & $\begin{array}{c}32.9 \\
{[27.3-35.0]}\end{array}$ & NS \\
\hline Prepregnancy BMI $\left(\mathrm{kg} / \mathrm{m}^{2}\right)$ & $\begin{array}{c}24.8 \\
{[22.5-26.2]}\end{array}$ & $\begin{array}{c}27.9 \\
{[23.4-32.9]}\end{array}$ & $P=.000$ \\
\hline Cigarette smoker & $35(73 \%)$ & $12(50 \%)$ & $P=.028$ \\
\hline Nulliparous & $29(60.4 \%)$ & $22(91.6 \%)$ & $P=.013$ \\
\hline Parous & $19(39.6 \%)$ & $2(8.4 \%)$ & \\
\hline Family history of PE & 0 & 0 & - \\
\hline \multicolumn{4}{|l|}{ Conception } \\
\hline Spontaneous & $42(87.5 \%)$ & $24(100 \%)$ & \multirow{2}{*}{$P=.090$} \\
\hline IVF & $6(12.5 \%)$ & 0 & \\
\hline \multicolumn{4}{|l|}{ Medical history } \\
\hline Diabetes mellitus & 0 & 0 & \multirow{2}{*}{-} \\
\hline Thrombophilia & 0 & 1 & \\
\hline \multicolumn{4}{|l|}{ Mode of delivery } \\
\hline Vaginal birth $(n)$ & $33(68.7 \%)$ & $8(33.3 \%)$ & \multirow{2}{*}{$P=.013$} \\
\hline Caesarean delivery $(n)$ & $15(31.3 \%)$ & $16(66.6 \%)$ & \\
\hline Gestational age at delivery (wk) & $\begin{array}{c}40.2 \\
{[37.2-42.0]}\end{array}$ & $\begin{array}{c}38.1 \\
{[32.1-40.6]}\end{array}$ & \multirow{4}{*}{$P=.000$} \\
\hline$<37 \mathrm{wk}(n)$ & 0 & 7 & \\
\hline$<34 \mathrm{wk}(n)$ & 0 & 2 & \\
\hline Birth weight (g) & $\begin{array}{c}3410 \\
{[2880-4250]}\end{array}$ & $\begin{array}{c}2780 \\
{[980-3950]}\end{array}$ & \\
\hline$>10$ th percentile $(n)$ & 48 & 11 & \multirow{3}{*}{$P=.020$} \\
\hline$<10$ th percentile $(n)$ & 0 & 11 & \\
\hline$<5$ th percentile $(n)$ & 0 & 2 & \\
\hline
\end{tabular}

Serum levels of Cystatin-C and VCAM-1 were significantly higher in patients with $\mathrm{PE}$ as compared to gestational age-matched controls (Figures 1(b) and 1(c)). The median concentration of serum Cystatin-C was $909.173 \mathrm{ng} / \mathrm{mL}$ (range $1964.1 \mathrm{ng} / \mathrm{mL}$ ) in $\mathrm{PE}$ cases and $480.0 \mathrm{ng} / \mathrm{mL}$ (range $1231.610 \mathrm{ng} / \mathrm{mL})$ in controls $(P<.001)$. The median concentration of VCAM-1 was $832.3 \mathrm{ng} / \mathrm{mL}$ (range $1193 \mathrm{ng} / \mathrm{mL}$ ) in $\mathrm{PE}$ cases and $738.8 \mathrm{ng} / \mathrm{mL}$ (range $563.7 \mathrm{ng} / \mathrm{mL}$ ) in controls $(P=.024)$. Maternal levels of Pappalysin-A did not differ significantly between $\mathrm{PE}$ cases (median $234.4 \mathrm{ng} / \mathrm{mL}$, range $485.9 \mathrm{ng} / \mathrm{mL}$ ) and controls (median $74.9 \mathrm{ng} / \mathrm{mL}$, range $466.9 \mathrm{ng} / \mathrm{mL})(P=.064)$ (Figure $1(\mathrm{~d}))$. ROC curves were calculated and AUC values with corresponding standard errors are presented in Figure 2. In order to discriminate between cases at risk for PE and normal controls, cut-off values of $546.880 \mathrm{ng} / \mathrm{mL}$ for Cystatin-C, $1059.880 \mathrm{ng} / \mathrm{mL}$ for sVCAM, and $220.854 \mathrm{ng} / \mathrm{mL}$ for Pappalysin-A were chosen, which provided sensitivity of $91.7 \%, 41.7 \%$, and $54.2 \%$ and specificity of $85.7 \%, 100 \%$, and $95 \%$, respectively.

Apart from the models analyzed using as input the measurements of each protein independently, 3 additional models were considered for binary regression analysis. The results obtained showed that all three new models had better performance than the simple random sampling procedure (Asymp. Sig < 0,05 in the above AUC). When binary logistic regression was performed using the patients' clinical data (BMI, smoking, and parity), risk assessment for PE was found to be statistically affected by maternal BMI. This model allowed the correct classification of $87.7 \%$ of women in the $\mathrm{PE}$ or the control group. Taking into consideration the data obtained from biomarker analysis (Cystatin-C, Pappalysin$\mathrm{A}$, and sVCAM-1) risk assessment for PE was statistically affected only by Cystatin-C. This model allowed the correct classification of $84.9 \%$ of pregnant women in the PE or the normotensive group. When all variables (biochemical and clinical) were taken into consideration, risk assessment for $\mathrm{PE}$ was found to be statistically affected by Cystatin-C and maternal BMI. The model which includes these parameters allows for the classification of $93.3 \%$ of pregnant women in the normotensive or the PE group.

When all the above models were analyzed after excluding the 2 cases with early PE, the variables that affect the probability of having PE were found to be similar in all three models.

All models showed similar AUC values implying that they may all estimate statistically accurately the risk assessment on PE (Figure 3). Since the model which includes patients' clinical data and biochemical measurements allows the correct classification of $93.3 \%$ of pregnant women in the PE or the normotensive group, it should be considered as the most preferable one. 


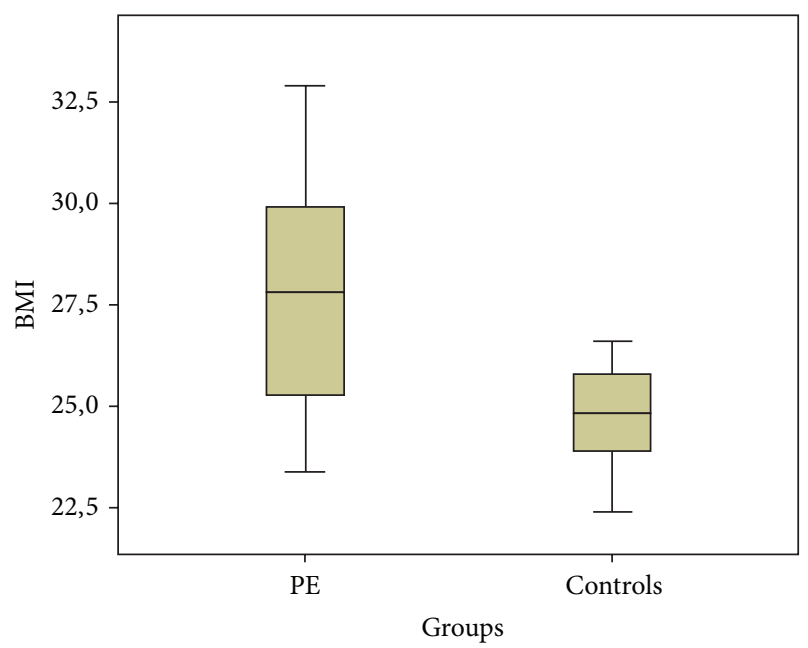

(a)

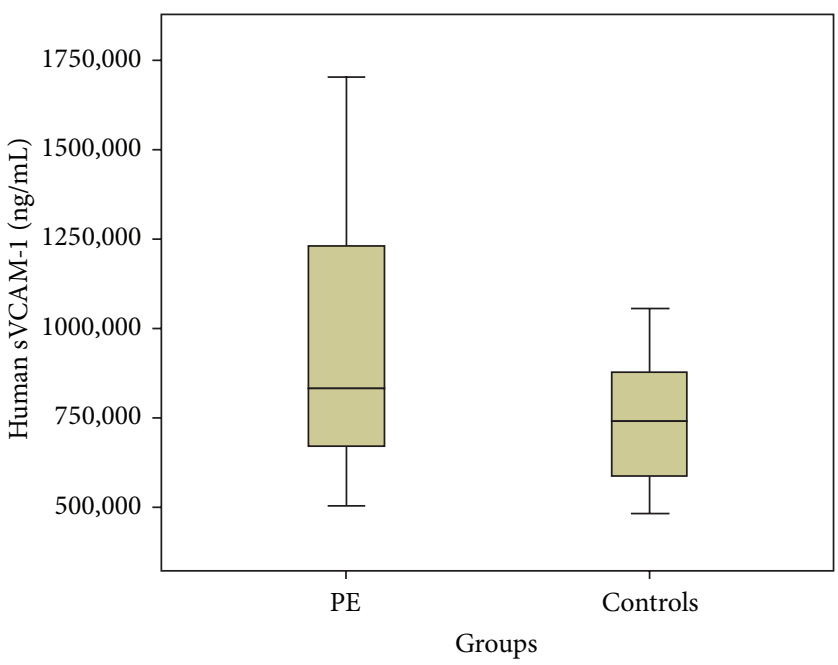

(c)

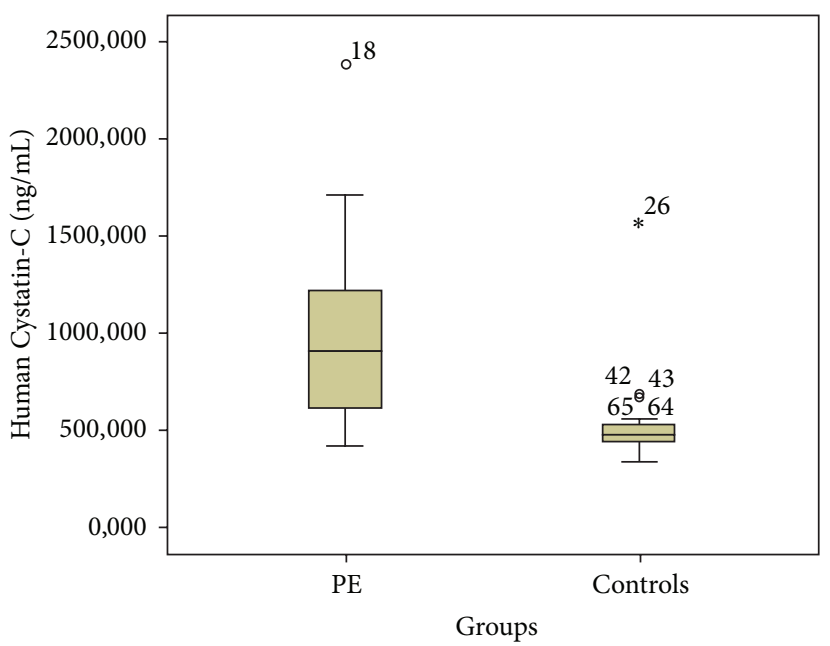

(b)

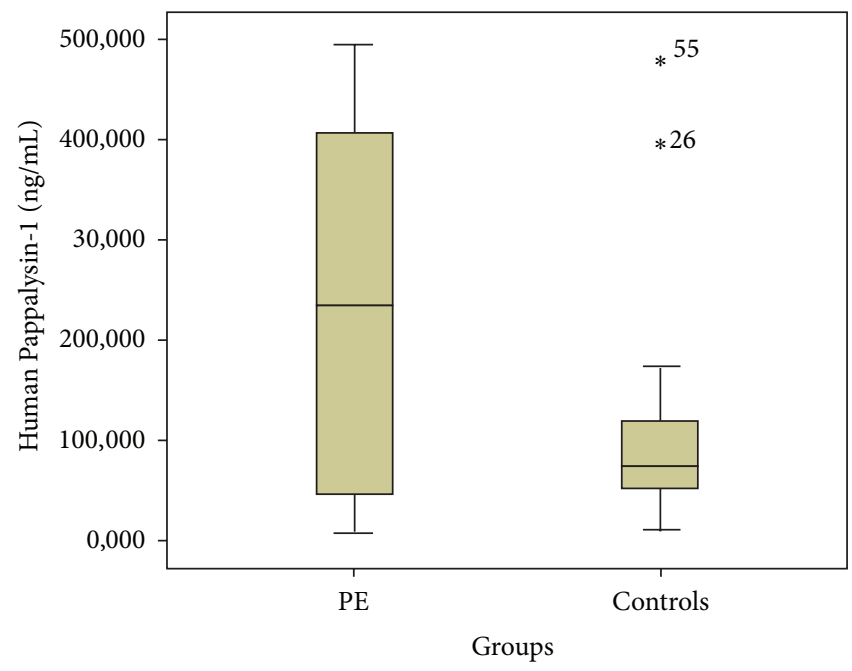

(d)

FIgURE 1: Box-plot of maternal prepregnancy BMI (a), Cystatin-C (b), VCAM-1 (c), and Pappalysin-A (d) in 24 pregnant women that subsequently developed PE and 48 uncomplicated pregnancies. The box represents the lower and upper quartiles, the medians are indicated by a line inside each box; the whiskers represent the 10th and 90th percentiles. Outliers, depicted as asterisks, are values more than 1.5 box lengths from either ridge of the box.

\section{Discussion}

In the present retrospective study, 1st trimester serum levels of Cystatin-C, VCAM-1, and Pappalysin-A in women who subsequently developed $\mathrm{PE}$ and gestational age-matched controls were analysed. These proteins were chosen from the list of potential biomarkers for PE provided by Rasanen et al. for the identification of women with early and severe preclinical and/or clinical PE, since they are involved in different pathways leading to PE, showing statistically significant differential expression in PE cases, and monoclonal antibodies for their measurement are commercially available [16].

In the PE group, 22 out of 24 patients developed lateonset $\mathrm{PE}$ which is significantly more common and, despite being often mild, can be associated with significant clinical morbidity. Two patients manifested PE between 32 and 34 weeks of gestation but these two cases do not significantly affect the results of this study.

Our findings indicate that circulating VCAM-1 levels were significantly increased in $\mathrm{PE}$ as compared to normal pregnancy. Lyall et al. were the first to show that sVCAM1 was elevated in the serum of patients with severe PE, as compared to the mild form of the disease, or normal pregnancy [18]. Krauss et al. found significantly elevated levels of sVCAM-1 in the plasma of pregnant women 3-15 weeks before the onset of clinical symptoms of PE [19]. sVCAM-1 is a member of the immunoglobulin superfamily and functions as a transmembrane receptor in vascular endothelial cell membranes. Increased concentrations of sVCAM-1 may reflect increased expression of this protein on the endothelial surface. In contrast, Haller et al. reported that sVCAM-1 expression was not increased in the serum of PE patients [20]. 


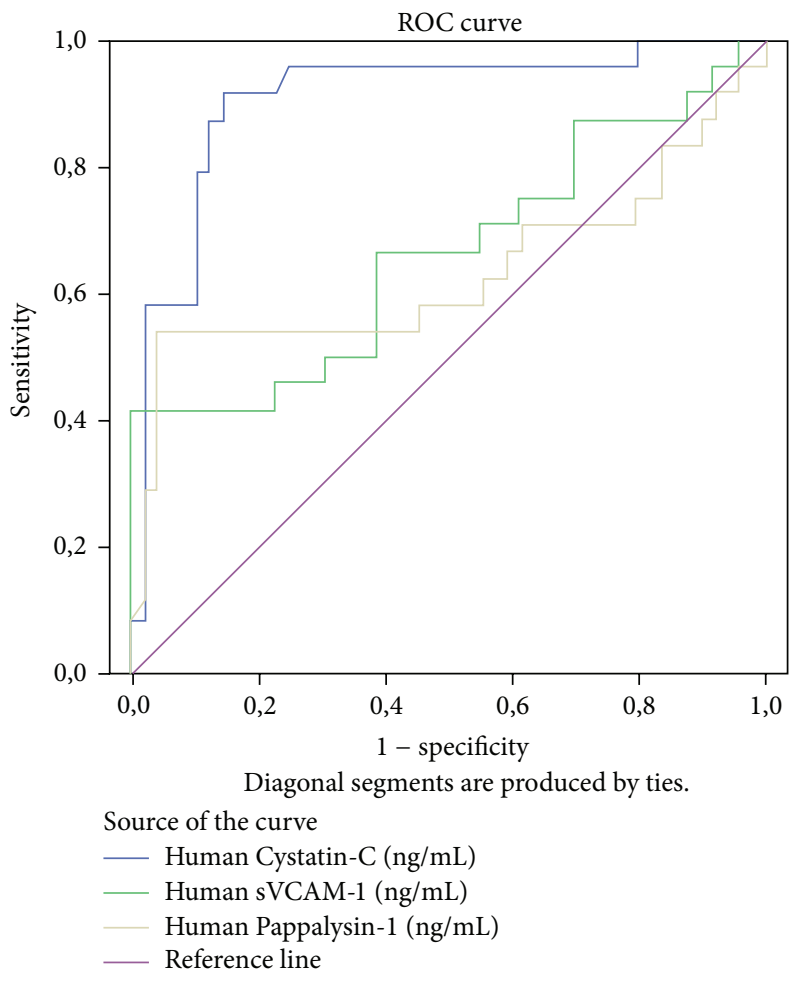

\begin{tabular}{|c|c|c|c|c|c|}
\hline \multirow[b]{3}{*}{ Test result variable(s) } & \multirow[b]{3}{*}{ Area } & \multicolumn{4}{|c|}{ Area under the curve } \\
\hline & & \multirow[b]{2}{*}{ Std. error ${ }^{a}$} & \multirow[b]{2}{*}{$\begin{array}{l}\text { Asymptotic } \\
\text { sig. }\end{array}$} & \multicolumn{2}{|c|}{$\begin{array}{l}\text { Asymptotic } 95 \% \\
\text { confidence interval }\end{array}$} \\
\hline & & & & $\begin{array}{l}\text { Lower } \\
\text { bound }\end{array}$ & $\begin{array}{l}\text { Upper } \\
\text { bound }\end{array}$ \\
\hline Human Cystatin-C (ng/mL) & 0.909 & 0.040 & 0.000 & 0.831 & 0.988 \\
\hline Human sVCAM-1 (ng/mL) & 0.663 & 0.074 & 0.024 & 0.518 & 0.809 \\
\hline Human Pappalysin-1 (ng/mL) & 0.634 & 0.083 & 0.064 & 0.472 & 0.796 \\
\hline
\end{tabular}

a: under the nonparametric assumption

b: null hypothesis: true area $=0.5$

FIgURE 2: Receiver-operating characteristics (ROC) curves showing the sensitivity and specificity of first-trimester Cystatin-C, VCAM-1, and Pappalysin-A as biomarkers for the prediction of women at risk of PE.

In the present study, the levels of Pappalysin-A in early pregnancy maternal serum in women that subsequently developed PE were decreased. However, since the association between Pappalysin-A serum levels and PE was relatively weak, the clinical usefulness of this marker is limited. Spencer et al. reported a small increase in likelihood ratio of developing PE with decreasing levels of Pappalysin-A [21]. More recent studies, however, have shown that although reduced first-trimester serum levels of Pappalysin-A are associated with PE, levels are also low in other complications of pregnancy [22-24]. It has been suggested that Pappalysin$A$ is more useful as a marker of IUGR than of PE.

Our data show that Cystatin- $C$ could be a reliable firsttrimester marker for PE. Cystatin-C is a protease inhibitor widely used by clinicians as a sensitive marker for renal function and for the estimation of glomerular filtration rate. Since all women had normal renal function, increased levels of Cystatin-C may be attributed to an increased placental production. This supports the hypothesis that the balance between trophoblast protease production and decidual protease inhibitor activity may have an important biologic role in trophoblast development and a derangement in this balance may predispose to poor trophoblast development and $\mathrm{PE}$ $[25,26]$.

Consistent with previous reports, a significant increased maternal BMI was found in women at risk for PE [27-29]. Statistical analysis showed that although the use of maternal clinical characteristics for risk assessment for PE showed higher AUC as compared to each of the 3 biochemical markers measured in the present study, simultaneous testing using maternal BMI and Cystatin-C can correctly classify $93.3 \%$ of pregnant women in the $\mathrm{PE}$ or the normotensive group.

The major limitations of the present study are the small number of samples analysed and the fact that clinical data 


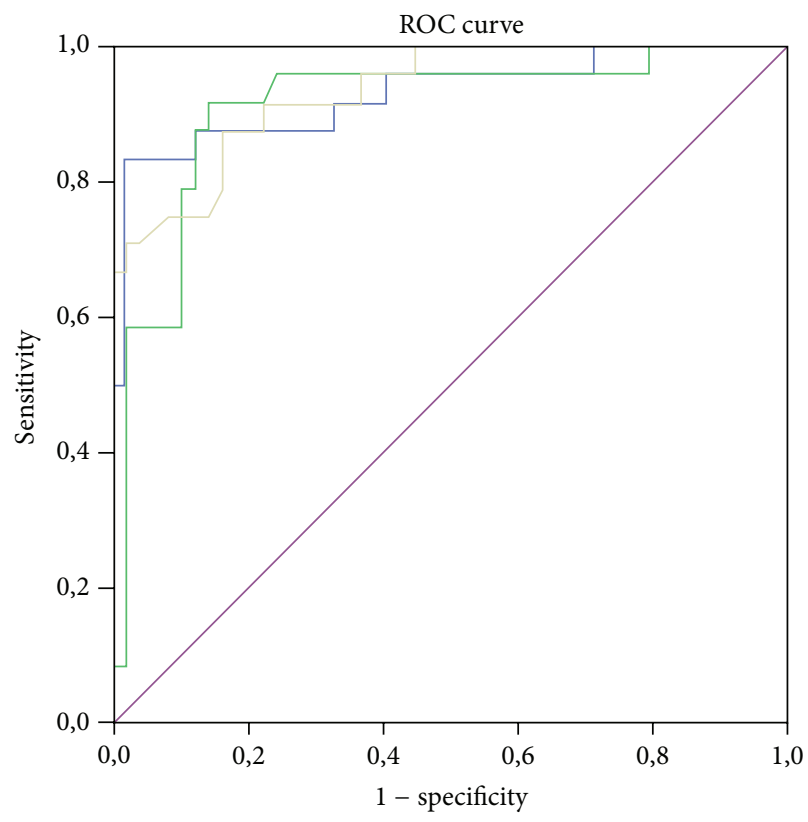

Diagonal segments are produced by ties.

Source of the curve

— Biomarkers tested and patients' clinical data

— Biomarkers tested

Patients' clinical data

— Reference line

\begin{tabular}{|c|c|c|c|c|c|}
\hline \multicolumn{6}{|c|}{ Area under the curve } \\
\hline \multirow[b]{2}{*}{ Test result variable(s) } & \multirow[b]{2}{*}{ Area } & \multirow[b]{2}{*}{ Std. error ${ }^{a}$} & \multirow{2}{*}{$\begin{array}{l}\text { Asymptotic } \\
\text { sig. }^{\text {b }}\end{array}$} & \multicolumn{2}{|c|}{$\begin{array}{c}\text { Asymptotic 95\% } \\
\text { confidence interval }\end{array}$} \\
\hline & & & & Lower bound & Upper bound \\
\hline $\begin{array}{l}\text { Biomarkers tested }+ \\
\text { patients' clinical data }\end{array}$ & 0,928 & 0,037 & 0,000 & 0,856 & 1,000 \\
\hline Biomarkers tested & 0,909 & 0,040 & 0,000 & 0,831 & 0,988 \\
\hline Patients' clinical data & 0,933 & 0,029 & 0,000 & 0,876 & 0,991 \\
\hline
\end{tabular}

a: under the nonparametric assumption

b: null hypothesis: true area $=0.5$

FIGURE 3: Receiver-operating characteristics (ROC) curves showing the sensitivity and specificity of first-trimester testing using A. patients' clinical characteristics, B. biochemical markers, and C. clinical and biochemical variables simultaneously, for the prediction of women at risk of PE.

known to be associated with $\mathrm{PE}$, such as 1st trimester maternal mean arterial pressure (MAP) and mean uterine artery (UtA) Doppler pulsatility index (PI) measurements, are missing. Studies with larger sample sizes, especially with early onset PE, will be necessary to assess the definitive potential of these biomarkers for early detection of PE and risk assessment.

Since PE is a multifactorial and polysystemic pregnancy complication, more than one biomarker is needed in order to identify women at risk. As already mentioned, the 3 biomarkers tested in the present study were chosen on the basis of their statistically significant differential expression using proteomics. Nevertheless, other potential biomarkers, already identified using proteomics, should be validated.

\section{Conflict of Interests}

The authors declare that they have no conflict of interests.

\section{Acknowledgment}

The study was funded by "Aristeia," through the operation program "Education and Lifelong Learning" cofinanced by EU and the Greek state.

\section{References}

[1] B. Sibai, G. Dekker, and M. Kupferminc, "Pre-eclampsia," The Lancet, vol. 365, no. 9461, pp. 785-799, 2005. 
[2] E. Stekkinger, M. Zandstra, L. L. H. Peeters, and M. E. A. Spaanderman, "Early-onset preeclampsia and the prevalence of postpartum metabolic syndrome," Obstetrics and Gynecology, vol. 114, no. 5, pp. 1076-1084, 2009.

[3] E. Berzan, R. Doyle, and C. M. Brown, "Treatment of preeclampsia: current approach and future perspective," Current Hypertension Reports, vol. 16, no. 9, p. 473, 2014.

[4] J. L. Maron, K. L. Johnson, D. Slonim et al., "Gene expression analysis in pregnant women and their infants identifies unique fetal biomarkers that circulate in maternal blood," The Journal of Clinical Investigation, vol. 117, no. 10, pp. 3007-3019, 2007.

[5] C. Y. T. Ong, A. W. Liao, K. Spencer, S. Munim, and K. H. Nicolaides, "First trimester maternal serum free $\beta$ human chorionic gonadotrophin and pregnancy associated plasma protein a as predictors of pregnancy complications," British Journal of Obstetrics and Gynaecology, vol. 107, no. 10, pp. 12651270, 2000.

[6] A. Pilalis, A. P. Souka, P. Antsaklis et al., "Screening for preeclampsia and fetal growth restriction by uterine artery Doppler and PAPP-A at 11-14 weeks' gestation," Ultrasound in Obstetrics and Gynecology, vol. 29, no. 2, pp. 135-140, 2007.

[7] L. C. Y. Poon, N. A. Kametas, N. Maiz, R. Akolekar, and K. H. Nicolaides, "First-trimester prediction of hypertensive disorders in pregnancy," Hypertension, vol. 53, no. 5, pp. 812818,2009

[8] S. Sifakis, R. Akolekar, D. Kappou, N. Mantas, and K. H. Nicolaides, "Maternal serum insulin-like growth factor-binding protein-3 (IGFBP-3) at 11-13 weeks in preeclampsia," Journal of Human Hypertension, vol. 26, no. 4, pp. 253-258, 2012.

[9] S. Sifakis, R. Akolekar, N. Mantas, D. Kappou, and K. H. Nicolaides, "Maternal serum human placental growth hormone (hPGH) at 11 to 13 weeks of gestation in preeclampsia," Hypertension in Pregnancy, vol. 30, no. 1, pp. 74-82, 2011.

[10] K. Spencer, N. J. Cowans, and A. Stamatopoulou, "ADAM12s in maternal serum as a potential marker of pre-eclampsia," Prenatal Diagnosis, vol. 28, no. 3, pp. 212-216, 2008.

[11] D. M. Carty, E. Schiffer, and C. Delles, "Proteomics in hypertension," Journal of Human Hypertension, vol. 27, no. 4, pp. 211-216, 2013.

[12] J. Klein, B. Buffin-Meyer, W. Mullen et al., "Clinical proteomics in obstetrics and neonatology," Expert Review of Proteomics, vol. 11, no. 1, pp. 75-89, 2014.

[13] A. Kolialexi, A. Mavrou, G. Spyrou, and G. T. Tsangaris, "Mass spectrometry-based proteomics in reproductive medicine," Mass Spectrometry Reviews, vol. 27, no. 6, pp. 624-634, 2008.

[14] V. Kolla, P. Jenö, S. Moes, O. Lapaire, I. Hoesli, and S. Hahn, "Quantitative proteomic (iTRAQ) analysis of 1st trimester maternal plasma samples in pregnancies at risk for preeclampsia," Journal of Biomedicine and Biotechnology, vol. 2012, Article ID 305964, 8 pages, 2012.

[15] M. Blumenstein, M. T. McMaster, M. A. Black et al., "A proteomic approach identifies early pregnancy biomarkers for preeclampsia: novel linkages between a predisposition to preeclampsia and cardiovascular disease," Proteomics, vol. 9, no. 11, pp. 2929-2945, 2009.

[16] J. Rasanen, A. Girsen, X. Lu et al., "Comprehensive maternal serum proteomic profiles of preclinical and clinical preeclampsia," Journal of Proteome Research, vol. 9, no. 8, pp. 4274-4281, 2010.

[17] N. Papantoniou, V. Bagiokos, K. Agiannitopoulos et al., "RASSF1A in maternal plasma as a molecular marker of preeclampsia," Prenatal Diagnosis, vol. 33, no. 7, pp. 682-687, 2013.

[18] F. Lyall, R. G. Hayman, J. R. Ashworth, E. Duffie, and P. N. Baker, "Relationship of cell adhesion molecule expression to endothelium-dependent relaxation in normal pregnancy and pregnancies complicated with preeclampsia or fetal growth restriction," Journal of the Society for Gynecologic Investigation, vol. 6, no. 4, pp. 196-201, 1999.

[19] T. Krauss, W. Kuhn, C. Lakoma, and H. G. Augustin, "Circulating endothelial cell adhesion molecules as diagnostic markers for the early identification of pregnant women at risk for development of preeclampsia," The American Journal of Obstetrics and Gynecology, vol. 177, no. 2, pp. 443-449, 1997.

[20] H. Haller, E.-M. Ziegler, V. Homuth et al., "Endothelial adhesion molecules and leukocyte integrins in preeclamptic patients," Hypertension, vol. 29, no. 1, part 2, pp. 291-296, 1997.

[21] K. Spencer, N. J. Cowans, and K. H. Nicolaides, "Low levels of maternal serum PAPP-A in the first trimester and the risk of pre-eclampsia," Prenatal Diagnosis, vol. 28, no. 1, pp. 7-10, 2008.

[22] J. F. Carbone, M. G. Tuuli, R. Bradshaw, J. Liebsch, and A. O. Odibo, "Efficiency of first-trimester growth restriction and low pregnancy-associated plasma protein-A in predicting small for gestational age at delivery," Prenatal Diagnosis, vol. 32, no. 8, pp. 724-729, 2012.

[23] A. O. Odibo, A. Francis, A. G. Cahill, G. A. MacOnes, J. P. Crane, and J. Gardosi, "Association between pregnancy complications and small-for-gestational-age birth weight defined by customized fetal growth standard versus a population-based standard," Journal of Maternal-Fetal and Neonatal Medicine, vol. 24, no. 3, pp. 411-417, 2011.

[24] J. K. Ranta, K. Raatikainen, J. Romppanen, K. Pulkki, and S. Heinonen, "Decreased PAPP-A is associated with preeclampsia, premature delivery and small for gestational age infants but not with placental abruption," European Journal of Obstetrics Gynecology and Reproductive Biology, vol. 157, no. 1, pp. 48-52, 2011.

[25] N. Franceschini, C. Qiu, D. A. Barrow, and M. A. Williams, "Cystatin C and preeclampsia: a case control study," Renal Failure, vol. 30, no. 1, pp. 89-95, 2008.

[26] B. Thilaganathan, B. Wormald, C. Zanardini, J. Sheldon, E. Ralph, and A. T. Papageorghiou, "Early-pregnancy multiple serum markers and second-trimester uterine artery doppler in predicting preeclampsia," Obstetrics and Gynecology, vol. 115, no. 6, pp. 1233-1238, 2010.

[27] S. Chandrasekaran, L. D. Levine, C. P. Durnwald, M. A. Elovitz, and S. K. Srinivas, "Excessive weight gain and hypertensive disorders of pregnancy in the obese patient," Journal of MaternalFetal and Neonatal Medicine, 2014.

[28] M. Lucovnik, I. Blickstein, I. Verdenik, L. Steblovnik, A. T. Bregar, and N. Tul, "Impact of pre-gravid body mass index and body mass index change on preeclampsia and gestational diabetes in singleton and twin pregnancies," The Journal of Maternal-Fetal \& Neonatal Medicine, vol. 27, no. 18, pp. 19011904, 2014.

[29] V. L. Bilano, E. Ota, T. Ganchimeg, R. Mori, and J. P. Souza, "Risk factors of pre-eclampsia/eclampsia and its adverse outcomes in low- and middle-income countries: a WHO secondary analysis," PLoS ONE, vol. 9, no. 3, Article ID e91198, 2014. 


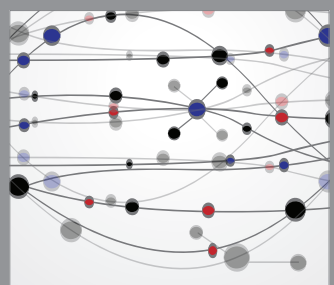

The Scientific World Journal
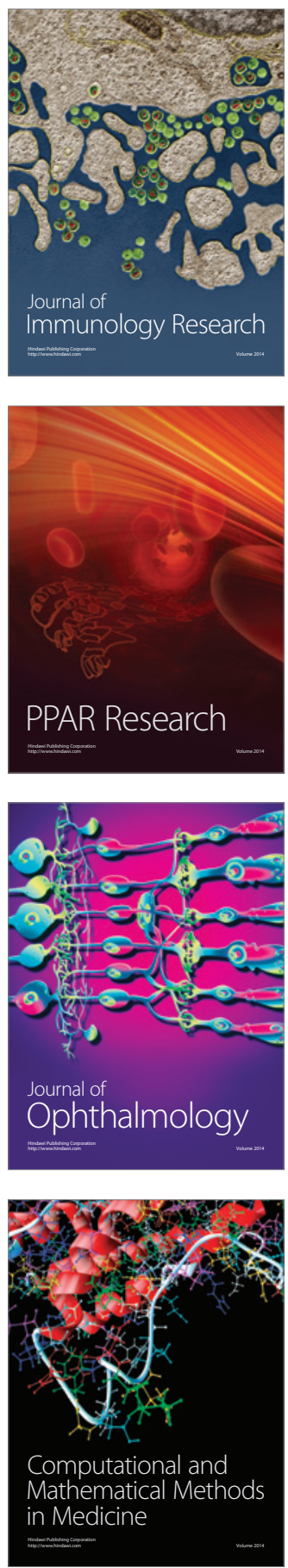

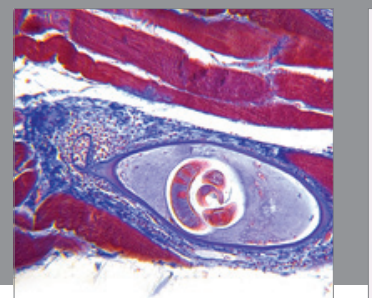

Gastroenterology

Research and Practice
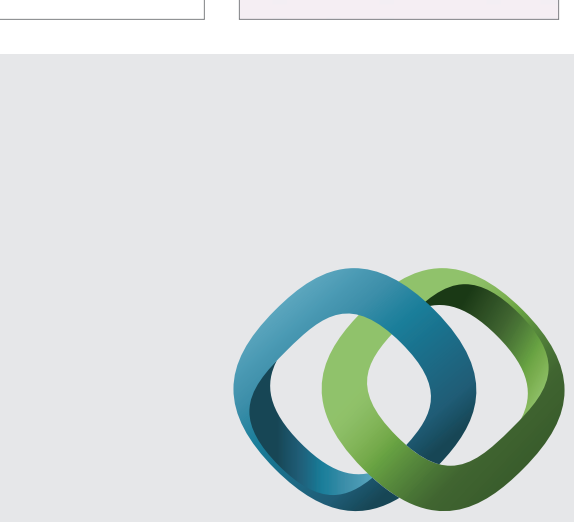

\section{Hindawi}

Submit your manuscripts at

http://www.hindawi.com
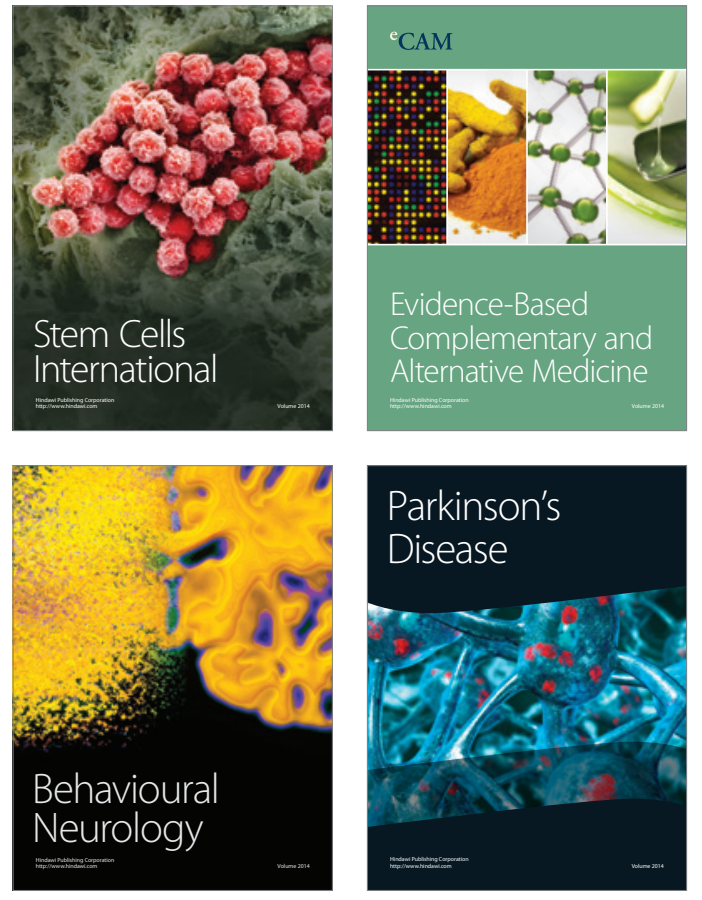
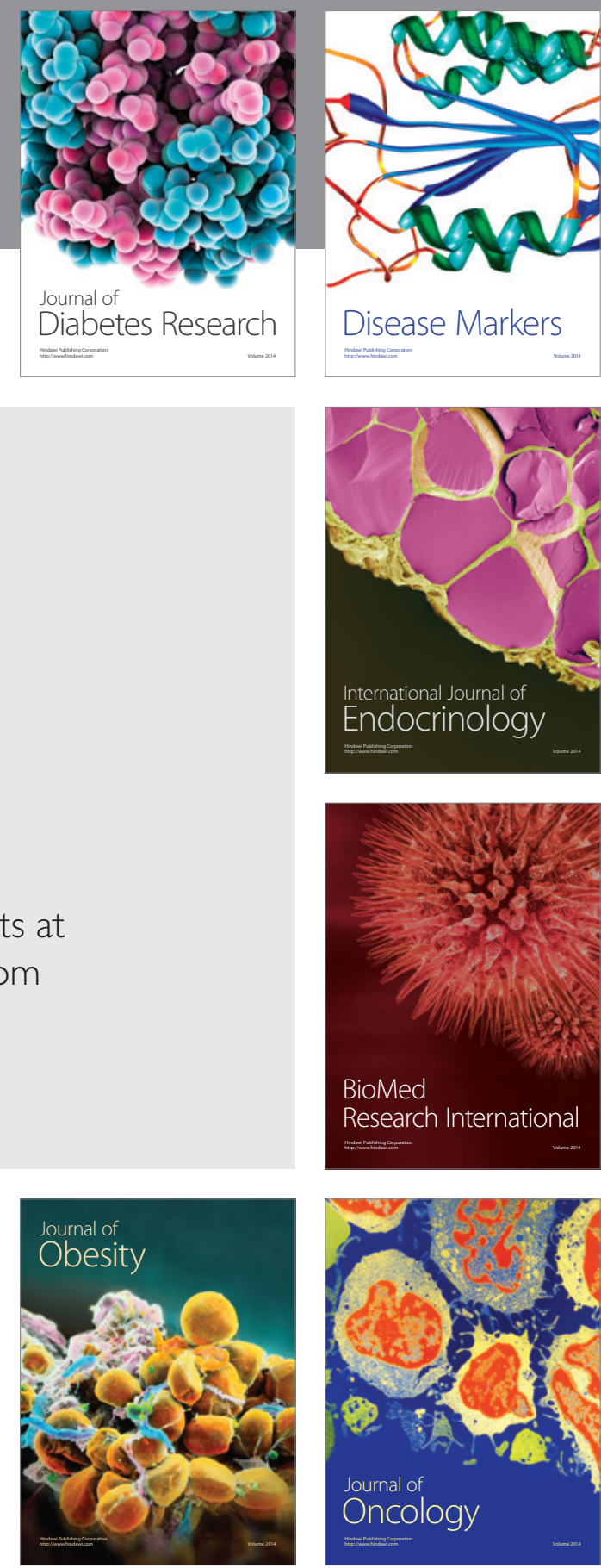

Disease Markers
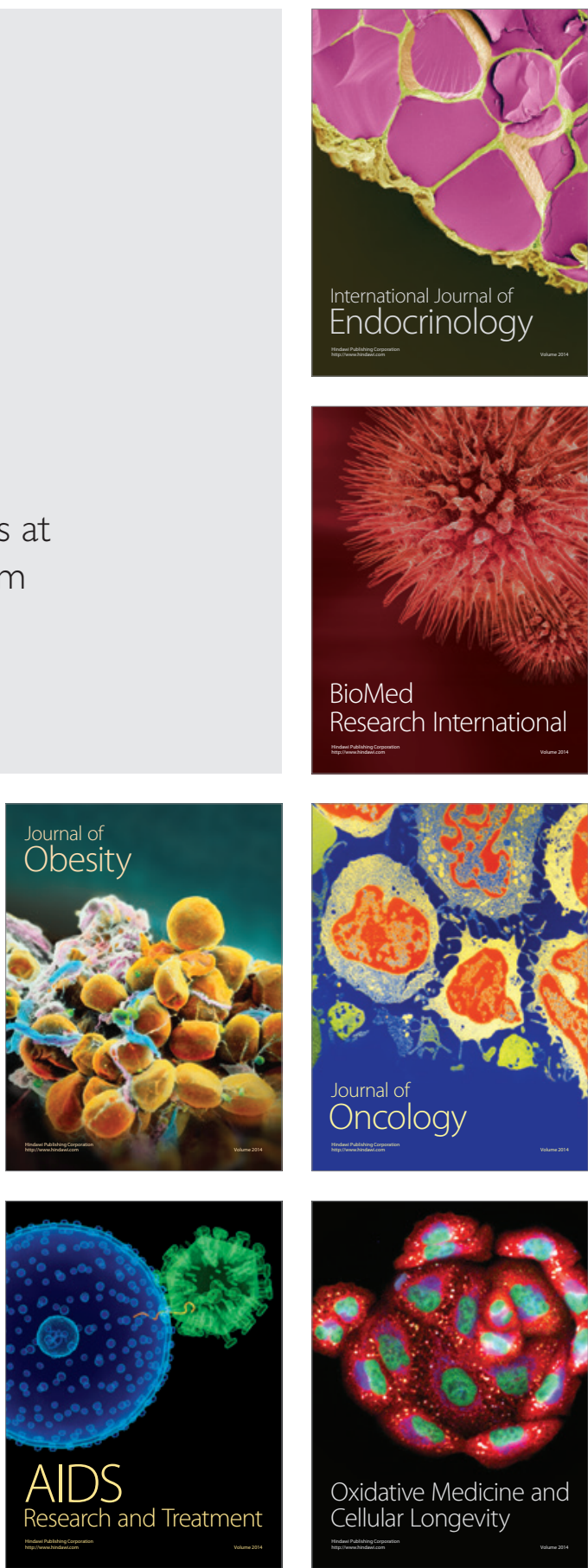